\begin{tabular}{|l|c|c|c|}
\hline Tỷ lệ & $12,1 \%$ & $87,9 \%$ & $100 \%$ \\
\hline
\end{tabular}

Nhóm nghiên cứu ghi nhận có $12,1 \%$ BN gãy lại xương, hầu hết BN không phát sinh tình trạng gãy lại. Tuy nhiên các năm tiếp theo giảm dần tỷ lệ tái khám và điều trị loãng xương, tăng dần tỉ lệ gãy lại xương. Vị trí xương gãy mới là cổ xương đùi, đâu dưới xương quay hay lún xẹp đốt sống. Đồng thời nhóm chúng tôi phân tích sâu giữa việc điều trị loãng xương và gãy lại xương.

Bảng 3.8. Thống kê BN loãng xương có điều trị hoặc bỏ trị trên tỉ lệ gãy lại xương lân 2 ( $n=149)$

\begin{tabular}{|c|c|c|}
\hline & $\begin{array}{c}\text { Gãy lại } \\
\text { xương }\end{array}$ & $\begin{array}{c}\text { Không gãy } \\
\text { thếm }\end{array}$ \\
\hline Điều trị & $1(5,6 \%)$ & $111(84,7 \%)$ \\
\hline Bỏ trị & $17(94,4 \%)$ & $20(15,3 \%)$ \\
\hline Tống số/Tỷ lệ & $18 / 100 \%$ & $131 / 100 \%$ \\
\hline \multicolumn{2}{|c|}{ Trong tổng }
\end{tabular}

Trong tổng số $149 \mathrm{BN}$ loãng xương, nhóm nghiên cứu nhận thấy số BN gãy lại xương phần lớn là bỏ trị với $94,4 \%$ (trong $18 \mathrm{BN}$ ), trường hợp không gãy thêm hầu như đều tuân thủ việc điều trị loãng xương.

V. KẾT LUẬN
Qua 175 trường hợp nghiên cứu chúng tôi thấy rằng mức độ gãy xương tăng dần theo độ tuổi. Bên cạnh đó mật độ xương loãng chiếm tỷ lệ cao $85,1 \%$. Trong đó có $84,7 \%$ BN loãng xương tuân thủ điều trị và không gãy thêm lần nữa, 94,4\% BN bỏ điều trị loãng xương bị gãy thêm lần nữa. Vì vậy việc điều trị loãng xương trên BN lớn tuổi gãy xương vùng háng rất cần thiết, bên cạnh đó $\mathrm{BN}$ cần bám sát quá trình điều trị để giảm thiểu mức độ gãy xương thêm lần nữa.

\section{TÀI LIÊU THAM KHẢO}

1. Carlos J. Padilla Colón, PhD (2018), "Muscle and Bone Mass Loss in the Elderly Population: Advances in diagnosis and treatment", Biomed (Syd); 3: 40-49. doi:10.7150/jbm.23390.'

2. Greg AJ Robertson, Alexander M Wood (2018), "Hip hemi-arthroplasty for neck of femur fracture: What is the current evidence?", World J Orthop; November 18; 9(11): 235-244.

3. "Hemiarthroplasty of the Hip"; Wheeless' Textbook of Orthopaedics.

4. Stephen Richard Knight, Randeep Aujla, and Satya Prasad Biswas (2011), "Total Hip Arthroplasty - over 100 years of operative history", Orthop Rev (Pavia). 2011 Sep 6; 3(2): e16.

\title{
ĐÁNH GIÁ KẾT QUẢ SớM PHẪU THUÂT NộI SOI SAU PHÚC MẠC TẠO HİNH KHÚC NỐI BỂ THÂ̂N-NIỆU QUẢN
}

Tô Hoàng Dũng*, Vũ Sơn*, Đỗ Trường Thành** Phan Thanh Lương*, Nguyễn Việt Dũng***

\section{TÓM TẮT}

Mục tiêu: Đánh giá kết quả sớm phẫu thuật (PT) nội soi sau phúc mạc (NSSPM) tạo hình khúc nối bể thận-niệu quản (BT - NQ). Đối tượng và phương pháp nghiên cứu: mô tả hồi cứu 59 bệnh nhân (BN) được NSSPM điểu trị hẹp khúc nối BT - NQ. Kết quả: 57/59 BN được đánh giá là PT thành công, đạt tỷ lệ $96,61 \%$, 2/59 BN không có cải thiện trên lâm sàng. Không có tai biễn, biến chứng nghiểm trọng trong và sau mô. Kết luận: PTNSSPM tạo hình khúc nối niệu quản - bể thận cho tỷ lệ thành công cao, an toàn.

Tì̛ khóa: Phẫu thuật nội soi sau phúc mạc, hẹp khúc nối bể thận - niệu quản.

\section{SUMMARY}

\footnotetext{
*Trường Đại học Y Dược Thái Bình

**Bênh viện Việt Đức

***Hoc viện Quân y

Chịu trách nhiệm chính: Tô Hoàng Dũng

Email: tohoangdung2809@gmail.com

Ngày nhận bài: 20.10.2020

Ngày phản biện khoa học: 30.11 .2020

Ngày duyệt bài: 9.12.2020
}

\section{EVALUATE EARLY RESULTS OF RETROPERITONEAL LAPAROSCOPY SURGERY FOR URETEROPELVIC JUNCTION STENOSIS \\ Objective: Evaluate early results of} retroperitoneal laparoscopy surgery for ureteropelvic junction stenosis. Subjects and methods: retrospective descriptions of 59 patients with ureteropelvic junctionstenosis treated by retroperitoneal laparoscopy surgery. Results: 57/59 patients were evaluated as having successful surgery, reaching the rate of $96.61 \%$. There are no severe complications during and after surgery. Conclusion: retroperitoneal laparoscopy surgery is a safe and effective procedure for ureteropelvic junction stenosis. Keywords: retroperitoneal laparoscopy, ureteropelvic junction stenosis.

\section{I. Đă̆T VẤN ĐỀ}

Hẹp khúc nối $B T$ - NQ là một bệnh lý thường gặp trong niệu khoa[1]. Khúc nối hẹp làm cho sự lưu thông từ bể thận xuống niệu quản bị tắc nghẽn gây ứ nước ở thận, lâu dài dần đến suy giảm chức năng thận. Đặc điểm của bệnh là hiếm khi khúc nối chít hẹp hoàn toàn, do đó 
bệnh thường diễn tiến âm ỉ, chức năng thận giảm từ từ, có thể dẫn đến suy chức năng thận.

Có nhiều phương pháp để điều trị bệnh lý hẹp khúc nối BT - NQ. Trước đây PT mổ mở tạo hình khúc nối $\mathrm{BT}$ - NQ là phương pháp điêu trị phố biến nhất, với tỷ lệ thành công trên $95 \%[2]$. Tuy nhiên, nhược điểm của PT mổ mở là thời gian mổ kéo dài, BN mất nhiêu thời gian để hồi phục, sẹo mổ lớn gây ảnh hưởng về mặt thẩm mỹ.

Ngày nay với xu hướng điều trị ít xâm hại nhằm làm giảm thời gian nằm viện và giúp $B N$ nhanh chóng hồi phục, các phương pháp tạo hình qua nội soi ngày càng được áp dụng rộng rãi. Nhiều NC gần đây cho thây NSSPM tạo hình khúc nối có kết quả tương đương với phẫu thuật mổ mở và được xem là phẫu thuật tiêu chuẩn trong điều trị bệnh lý hẹp khúc nối $\mathrm{BT}-\mathrm{NQ}$ [2]. Do đó, chúng tôi tiến hành NC này với mục tiêu "Đánh giá kết quả sớm phẫu thuật nội soi sau phúc mạc tạo hinh khúc nối bể thận-niệu quản".

\section{II. Đốl TƯợNG VÀ PHƯƠNG PHÁP NGHIÊN CỨU}

\section{1. Đối tượng nghiên cứu}

- BN được chẩn đoán hẹp khúc nối BT - NQ có chỉ định phẫu thuật tạo hình.

- Điều trị bằng kỹ thuật NSSPM tạo hình khúc nối BT - NQ

- BN có hồ sơ lưu trữ tại BV Việt Đức từ 01/ 06/2017 đến ngày 30/06/2020, có đầy đủ thông tin.

\section{Phương pháp nghiên cứu:}

2.1. Thiết kế NC: mô tả hồi cứu.

\subsection{Các chỉ tiêu NC:}

- Tuổi, giới, triệu chứng cơ năng, lâm sàng thận to, mức độ ứ nước thận trước mổ trên siêu âm (theo tiêu chuẩn của Quaia [3]), UIV, CLVT (theo tiêu chuẩn phân loại của Valayer và Cendron [1]).

- Phương pháp phẫu thuật:

$\checkmark$ Cắt rời Anderson-Hynes kinh điển: cắt rời khúc nối kèm cắt nhỏ bể thận. $\checkmark$ Cắt rời Anderson-Hynes không kinh điển: cắt rời khúc nối và không cắt nhỏ bể thận.

$\checkmark$ Cắt rời cải biên: cắt rời niệu quản dưới khúc nối, chuyển vị bể thận niệu quản ra trước mạch máu cực dưới, không cắt bỏ khúc nối.

$\checkmark$ Tạo hình Y-V

- Thời gian phẫu thuật, mạch máu bất thường, biến chứng trong mổ, thời gian nằm viện, biến chứng sau mổ.

- Kết quả phẫu thuật: đánh giá triệu chứng lâm sàng, hình thái và chức năng thận qua siêu âm và UIV

- Đánh giá kết quả sớm sau phẫu thuât:

oThành công: lâm sàng tốt và cận lầm sàng không ghi nhận tắc nghẽn của khúc nối.

o Thất bại: lâm sàng không cải thiện hoặc cận lâm sàng ghi nhận tắc nghẽn của khúc nối.

3. Phân tích và xử lý số liệu: số liệu được thu thập và xử lý bằng phần mềm SPSS 20.0.

\section{KẾT QUẢ NGHIÊN CỨU}

NC với 59 BN được NSSPM tạo hình khúc nối $B T$ - NQ, trong đó 01 BN được mổ cả hai bên. Có 38 nam $(64,4 \%)$ và 21 nữ $(35,6 \%)$ với độ tuổi trung bình là $32,69 \pm 14,82$ tuồi.

Bảng 1. Triệu chứng lâm sàng $(n=59)$

\begin{tabular}{|c|c|c|c|}
\hline \multicolumn{2}{|c|}{ Triệu chứng } & $\mathbf{n}$ & $\mathbf{\%}$ \\
\hline \multirow{3}{*}{ Toàn thân } & Sốt & 2 & 3,33 \\
\cline { 2 - 4 } & Phù & 1 & 1,70 \\
\hline \multirow{4}{*}{ TC cơ năng } & Đái buốt & 7 & 11,90 \\
\cline { 2 - 4 } & Đái dắt & 2 & 3,39 \\
\cline { 2 - 4 } & Đái đục & 1 & 1,69 \\
\cline { 2 - 4 } & Đái máu & 2 & 3,39 \\
\cline { 2 - 4 } & Đau thắt lưng & 59 & 100 \\
\hline TC thực thể & Thận to & 45 & 76,30 \\
\hline
\end{tabular}

Nhân xét: Tất cả BN nhập viên đều có TC đau thắt lưng. Các TC ít gặp hơn có đái buốt $(11,9 \%)$ và đái dắt $(3,4 \%)$. Trên lâm sàng, triệu chứng thận to khám thấy trên $45 \mathrm{TH}$ chiếm tỷ lệ $76,3 \%$.

Bảng 2. Mức độ ứ nước thận trước mổ $(n=60)$

\begin{tabular}{|c|c|c|c|c|c|c|}
\hline \multirow{2}{*}{ Mức độ ứ nước } & \multicolumn{2}{|c|}{ Siêu âm } & \multicolumn{2}{c|}{ UIV } & \multicolumn{2}{c|}{ CLVT } \\
\cline { 2 - 7 } & $\mathbf{n}$ & $\mathbf{\%}$ & $\mathbf{n}$ & $\mathbf{\%}$ & $\mathbf{n}$ & $\mathbf{\%}$ \\
\hline Độ 1 & 14 & 23,3 & 16 & 26,7 & 14 & 23,3 \\
\hline Độ̂ 2 & 26 & 43,3 & 26 & 43,3 & 26 & 43,3 \\
\hline Dộ̂ 3 & 18 & 30,0 & 17 & 28,3 & 18 & 30,0 \\
\hline Độ̀ 4 & 2 & 3,4 & 1 & 1,7 & 2 & 3,4 \\
\hline
\end{tabular}

Nhận xét: Tất cả các BN trong nhóm NC đều được siêu âm trước mổ, trong đó, tỷ lệ $\mathrm{BN}$ thận ứ nước độ 2 , độ 3 trên siêu âm là cao nhất, lần lượt là $43,3 \%$ và $30 \%$. Chỉ có 2 BN chiếm $3,4 \%$ có ứ nước thân độ 4 trên siêu âm. Mức đô ứ nước trên CLVT tương tự trên siêu âm. Trên UIV, đa số $B N$ có thận ứ nước ở độ 2 với 26 trường hợp chiếm 43,3\%.

Bảng 3. Phương pháp mổ $(n=60)$

\begin{tabular}{|c|c|c|}
\hline Phương pháp mố & $\mathbf{n}$ & $\mathbf{\%}$ \\
\hline Cắt rời A - H không kinh điến & 34 & 56,7 \\
\hline Cắt rời A - H kinh điến & 13 & 21,7 \\
\hline
\end{tabular}




\begin{tabular}{|c|c|c|}
\hline Cắt rời cải biên & 11 & 18,3 \\
\hline Tạo hình $\mathrm{Y}-\mathrm{V}$ & 2 & 3,4 \\
\hline Tống & $\mathbf{6 0}$ & $\mathbf{1 0 0}$ \\
\hline
\end{tabular}

Nhận xét: Đa số BN được tiến hành tạo hình theo phương pháp có cắt rời $(96,6 \%)$, trong đó, cắt rời $\mathrm{A}-\mathrm{H}$ không kinh điển chiếm đa số $(56,7 \%)$. Có $21,7 \%$ số TH cắt rời khúc nối kèm cắt nhỏ bể thân.

Bảng 4. Đặc điểm kỹ thuật mổ $(n=60)$

\begin{tabular}{|c|c|}
\hline Đặc điểm & Giá trị \\
\hline Thời gian mổ trung bình (phút) & $100,92 \pm$ \\
22,61 \\
\hline Động mạch cực dưới $n(\%)$ & $8(13,3)$ \\
\hline Sỏi thận kèm theo $n(\%)$ & $3(5)$ \\
\hline
\end{tabular}

\begin{tabular}{|l|l|} 
Thời gian nằm viện trung bình (ngày) & $7,10 \pm 3,07$ \\
\hline
\end{tabular}

Nhận xét: thời gian mố trung bình là 100,92 $\pm 22,61$ phút, trong đó đa số BN có thời gian mổ dưới 120 phút, không có trường hợp nào thời gian mổ trên 180 phút.

Tổn thương sỏi thận kèm theo gặp trong mổ là 3 trường hợp (chiếm $5 \%$ ). Tất cả những $\mathrm{BN}$ này đều được lấy sỏi trong lúc mổ qua bơm rửa bể thận hoặc dùng dụng cụ nội soi lấy sỏi qua vết rạch bể thận. Trong NC ghi nhận $8 \mathrm{TH}$ có động mạch cực dưới bất thường gây hẹp $\mathrm{BT}-\mathrm{NQ}$.

Thời gian nằm viện trung bình là $7,10 \pm 3,07$ ngày, trong đó, đa số $\mathrm{BN}$ nằm viện từ 5-7 ngày.

Bảng 5. So sánh mức độ ứ nước thận trên siêu âm trước và sau mổ 3 tháng $(n=60)$

\begin{tabular}{|c|c|c|c|c|c|c|}
\hline \multirow{2}{*}{\multicolumn{2}{|c|}{ Đặc điểm }} & \multicolumn{2}{|c|}{ Trước mố } & \multicolumn{2}{|c|}{ Sau mố 3 tháng } & \multirow[b]{2}{*}{$\mathbf{p}$} \\
\hline & & $\mathbf{n}$ & $\%$ & $\mathbf{n}$ & $\%$ & \\
\hline \multirow{5}{*}{$\begin{array}{l}\text { Thận ứ } \\
\text { nước }\end{array}$} & Không giãn & 0 & 0 & 14 & 23,3 & \multirow{5}{*}{0,001} \\
\hline & Độ 1 & 14 & 23,3 & 33 & 55,0 & \\
\hline & Độ 2 & 26 & 43,3 & 11 & 18,3 & \\
\hline & Độ 3 & 18 & 30,0 & 2 & 3,3 & \\
\hline & Đồ 4 & 2 & 3,3 & 0 & 0 & \\
\hline
\end{tabular}

Nhận xét: Có sự cải thiện về mức độ ứ nước của thận trên siêu âm, sự khác biệt này là có ý nghĩa thống kê, $p<0,05$.

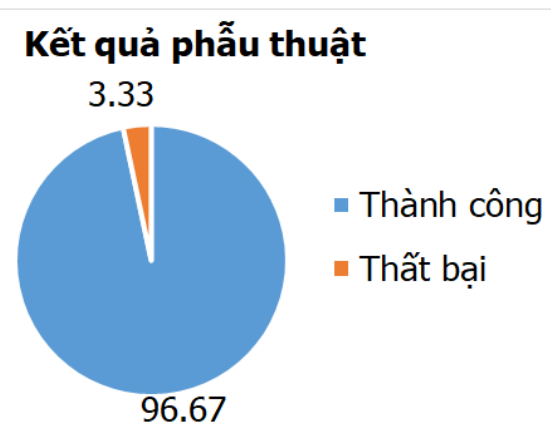

Biểu đồ 1. Kết quả phẫu thuât $(n=60)$

Nhận xét: Theo NC của chúng tôi, tỷ lệ thành công của phương pháp này là $96,7 \%$ (thành công ở 58/60 TH). Chỉ có 02 TH không cải thiên sau mổ.

Bảng 6. Kêt quả lâm sàng và CLS sau mổ 3 tháng $(n=59)$

\begin{tabular}{|c|c|c|c|}
\hline $\begin{array}{c}\text { Đăc } \\
\text { điểm }\end{array}$ & Cải thiện & $\begin{array}{c}\text { Không } \\
\text { cải thiện }\end{array}$ & Tổng \\
\hline Lâm sàng & 58 & 01 & 59 \\
\hline Siêu âm & 60 & 0 & 60 \\
\hline UIV & 59 & 01 & 60 \\
\hline
\end{tabular}

Nhận xét: Trên LS, hầu hết các BN đều có cải thiện sau mổ 03 tháng, chỉ có 01 BN sau mổ vẫn còn triệu chứng đái đục.Tất cả các $\mathrm{BN}$ đều không có triệu chứng tắc nghẽn trên siêu âm. Trên UIV, 59/60 TH có cải thiện sau mổ 03 tháng. Chỉ có 01 BN không cải thiện so với trước mổ.
Bảng 7. Biến chứng sau mổ $(n=60)$

\begin{tabular}{|c|c|c|}
\hline Biến chứng & $\mathbf{n}$ & $\mathbf{\%}$ \\
\hline Nhiếm trùng vết mổ & 10 & 16,7 \\
\hline Bục miệng nối & 6 & 10,0 \\
\hline Tràn khí dưới da & 3 & 5,0 \\
\hline
\end{tabular}

Nhân xét: trong quá trình mổ, chúng tôi không gặp bất kỳ tai biến nào. Sau mổ, biến chứng hay gặp nhất là nhiễm trùng vết mổ, gặp ở $10 \mathrm{TH}$, chiếm $16,7 \%$. Ngoài ra còn gặp các $\mathrm{BC}$ khác như bục miệng nối $(10,0 \%)$ và tràn khí dưới da $(5,0 \%)$. Tất cả các $B C$ này đều được điều trị nội khoa mà không cần mổ lại.

\section{BÀN LUẬN}

Trong điều trị bệnh lý hẹp khúc nối $B T$ - NQ, mổ mở vẫn được coi là phẫu thuật với tỷ lế thành công cao $(95 \%)$, tỉ lệ tái phát sau mổ thấp [2]. Tuy nhiên, phương pháp này có nhiều nhược điểm như ảnh hưởng đến tâm lý do phẫu thuật, để lại sẹo lớn ảnh hưởng đến thẩm mỹ, thời gian hồi phục kéo dài. Phẫu thuật NSSPM là một kỹ thuật ít xâm lấn, mang lại nhiều ưu điểm như giảm đau sau mổ, thời gian nằm viện ngắn, sẹo mổ nhỏ, không ảnh hưởng đến thẩm mỹ, mặt khác vẫn đem lại tỷ lệ thành công tương đương với mổ mở [4].

Kỹ thuật NSSPM cho phép tiếp cận trực tiếp với $B T-N Q$, do đó rút ngắn thời gian phấu thuật. Trong NC này, thời gian phẫu thuật trung bình là 
100,92 $\pm 22,61$ phút, tương đương với các tác giả khác [4],[5] và ngắn hơn so với mổ nội soi trong phúc mạc [6].

Trong NC này, có $8 \mathrm{TH}$ có động mạch bất thường bắt chéo ngang khúc nối. Những TH này đều được phẫu thuật cắt rời niệu quản dưới khúc nối, chuyển vị BT - NQ ra trước mạch máu cực dưới. Kết quả phẫu thuật đều thành công ở $8 \mathrm{TH}$ này.

Trong mổ, chúng tôi không gặp bất kỳ biến chứng nào nghiêm trọng phải dừng phẫu thuật. Gần đây, các tác giả thực hiện PTNS sau phúc mạc với số lượng lớn bệnh nhân đều ghi nhận không có biến chứng trong mổ, không có trường hợp nào phải chuyển mổ mở[7].

Kết quả có $57 \mathrm{TH}$ được đánh giá là thành công và 2 TH thất bại trong nghiên cứu này, tỉ lệ thành công là $96,67 \%$. Kết quả này tương đương với kết quả của một số tác giả khác như Nguyễn Đức Minh (2018) [2] và Soulié Michel (2001) [5]. Trong $2 \mathrm{TH}$ thất bại có $01 \mathrm{TH}$ có biểu hiện đái đục sau khi ra viện 3 tháng. BN này trước mổ có đái đục kèm $\mathrm{BC}$ niệu $(+++)$, đã được điều trị kháng sinh trước mổ. Tuy nhiên, sau mổ $\mathrm{BN}$ vẫn còn biểu hiện của nhiễm trùng niệu. $\mathrm{BN}$ này tiếp tục được điều trị bằng kháng sinh, $\mathrm{TC}$ đái đục không còn. $01 \mathrm{TH}$ thất bại khác là $\mathrm{BN}$ có thận không ngấm thuốc trên UIV trước mổ. Mặc dù không còn TCLS nhưng theo dõi trên UIV không thấy cải thiện so với trước mổ.

\section{KẾT LUÂN}

Với tỷ lệ thành công là $96,61 \%$, PT NSSPM đạt kết quả điều trị tương đương phẫu thuật mổ mở, đồng thời hạn chế được các tai biến biến chứng trong và sau mổ. Lựa chọn phẫu thuật NSSPM điều trị hẹp khúc nối BT - NQ mang lại nhiều lợi ích và có thể áp dụng rộng rãi trong điều kiện hiện nay ở Việt Nam

\section{TÀI LIÊU THAM KHẢO}

1. Ngố Đaí, Hải (2014). Đánh giá kết quả phẫu thuật nối soi sau phúc mạc tạo hình khúc nối niệu quản - bể thận kiểu cắt rời, Luận án Tiến sỹ Y học, Đại hoc Y dược Thành phố Hồ Chí Minh.

2. Nguyễn Đức, Minh, Vũ Nguyễn, Khải, $\mathrm{Ca}$, Hoàng Long (2018). Kết quả lâu dài điêu trị hẹp khúc nối bể thận - niệu quản qua nội soi sau phúc mac. Y hoc Viêt Nam, 465(1): 8-12.

3. Quaia Emilio, De Paoli Luca, Martingano Paola, et al.(2014). Obstructive uropathy, pyonephrosis, and reflux nephropathy in adults. In: Radiological imaging of the kidney, Springer: 353-89.

4. Zhang $X u$, Li Hong-Zhao, Wang Shao-Gang, et al.(2005). Retroperitoneal laparoscopic dismembered pyeloplasty: experience with 50 cases. Urology, 66(3): 514-7.

5. Soulié michel, salomon laurent, patard jeanjacques, et al.(2001). extraperitoneal laparoscopic pyeloplasty: a multicenter study of 55 procedures. the journal of urology, 166(1): 48-50.

6. jarrett thomas $w$, chan david $y$, charambura tanya c, et al.(2002). laparoscopic pyeloplasty: the first 100 cases. the journal of urology, 167(3): 1253-6.

7. chen zhi, chen xiang, qi lin, et al.(2011). retroperitoneoscopic dismembered pyeloplasty for pediatric ureteropelvic junction obstruction: a report of 85 cases. zhong nan da xue xue bao. yi xue ban= journal of central south university. medical sciences, 36(5): 430.

8. martina giorgio $r$, verze paolo, giummelli pierluigi, et al.(2011). a single institute's experience in retroperitoneal laparoscopic dismembered pyeloplasty: results with 86 consecutive patients. journal of endourology, 25(6): 999-1003.

\section{ĐẶC ĐIỂM VÀ KẾT QUẢ ĐIỀU TRI PHẪU THUÂTT KẾT XƯƠNG BÊN TRONG Ở BÊ̂NH NHÂN GÃ̃Y KÍN MẮT CÁ WEBER B}

\section{Đặng Minh Quang*, Đặng Hoàng Anh*, Phạm Đăng Ninh*}

\section{TÓM TẮT}

Mục tiêu: Đăc điểm và kết quả điều trị phẫu thuật kết xương bên trong ở bệnh nhân gãy mắt cá loai Weber $B$. Đối tượng và phương pháp nghiên cứu: nghiên cứu hồi cứu và tiến cứu 39 bệnh nhân được chẩn đoán gãy kín mắt cá chân Weber B điều trị bằng mổ mở kết xương bên trong tại khoa Chấn

*Bênh viên Quân y 103, Hoc viện Quân y.

Chịu trách nhiệm chính: Đặng Minh Quang

Email: minhquang.hvqy@gmail.com

Ngày nhận bài: 21.10 .2020

Ngày phản biện khoa họ: 27.11.2020

Ngày duyệt bài: 9.12.2020 thương chỉnh hình Bệnh viện Quân y 103. Kết quả: Tuổi trung bình 44,10 $\pm 14,32$ tuổi, đa số là nhóm 51 đến 65 tuổi chiếm $58,97 \%$, tiếp theo nhóm từ 21 đến 50 tuổi chiếm $30,77 \%$. Nguyên nhân gây tai nạn chủ yếu gặp là tai nạn thể thao $(46,15 \%)$ và tai nạn giao thông (38,46\%), bênh nhân nam giới $(61,54 \%)$. Bênh nhân vào viện sau tai nạn (76,92\%). Bệnh nhân được mổ sớm trong tuần đầu $(94,87 \%)$. Tỷ lệ bệnh nhẩn gãy mắt cá ngoài đơn thuần là $46,15 \%$ và̀ gãy mắt cá ngoài kết hợp với gãy mắt cá trong là $33,33 \%$. Kết quả điều trị xa sau phẫu thuật đa số có tỷ lệ khá trở lên $(93,1 \%)$. Điểm trung bình theo AOFAS là 90,82 \pm 8,3 với điểm thấp nhất là 75 và điểm cao nhất là 100 . Kết luâan: bênh nhân gãy kín mắt cá loại Weber $B$ được nhập viện sớm, phẫu thuật sớm cho kết quả xa 